\title{
ONLINE PERCEIVED VALUE IN THE LOW COST AIRLINE BUSINESS
}

\author{
Pei Chyi Lim, Graduate School of Business, University of Malaya, Malaysia \\ Brian C. Imrie, Sunway Business School, Sunway University, Malaysia \\ Nicholas Grigoriou, Monash University Sunway Campus, Malaysia
}

\begin{abstract}
The global airline industry has been hit hard by the global financial crisis (Goetz and Vowels, 2009). While full service airlines have struggled to be financially viable in this lean global environment, low cost carriers (LCCs) such as Air Asia and Firefly have changed the value proposition experienced by consumers when considering airline travel by lowering their costs and ticket prices to remain competitive. By choosing to fly with LCCs, consumers forego some of the value-added services provided by full service carriers such as complementary onboard meals, in-flight entertainment, and airline lounge services (Mathews, 2004). The emergence of low cost carriers (LCCs) has also changed the way in which consumers engage with airlines, particularly with regards to air ticket purchasing behaviour (Park et al., 2004). Due to time constraints and advancements in information technology, there is an increasing consumer preference in using the internet compare prices and purchase flight tickets (Goh, 2005).
\end{abstract}

We empirically examine Malaysian consumers' perceptions towards online perceived value in the LCC business. Perceive value is the consumer's overall assessment of the utility of a product based on perceptions of what is received and what is given (Zeithaml, 1988). In an e-commerce context, the consideraton of online perceived value is gaining in strategic prominenance due to an awareness that consumers increasingly compare product features and prices online. The provision of effective online search and browse methods are considered mechanisms that will enhance the perception of value (Cheng et al., 2008). The results offer a different perspective of the antecedents of online perceived value from that found in the extant literature. We found a strong correlation between LCC flight ticket pricing and online perceived value. Our findings have implications for managerial decision makers in LCCs. Managerial decision makers in LCCs must make their online service promises realistic, relevant, and deliverable.

The principal limitation inherent within this study was the use of convenience sampling. Consequently, the resulting sample is not representative of the broader Malaysian population in terms of gender, age, income, or educational level.

References available upon request 